\title{
Ethnic Minorities in America
}

\author{
Roudi Nazarinia Roy ${ }^{1}$ Elizabeth M. Dolan ${ }^{2}$
}

Published online: 2 August 2017

(C) Springer Science+Business Media, LLC 2017

The United State is perceived as a land of opportunity with freedoms for all. This special section brings together papers that examine how these opportunities and freedoms transpire among ethnic minority groups in the US. In this collection of papers, we have both qualitative and quantitative investigations. Quantitative data are from several sources including the National Longitudinal Survey of Youth (1997-2013) and the Fragile Families and Child Wellbeing Study, as well as data on populations we under sample in the current literature, such as the Asian Indian ethnic group from the Survey of Asian American Families (SAAF) conducted in New York and New Jersey between 2011 and 2014. Several of the investigation have used longitudinal data to focus on ethnic minority experiences over time.

Muruthi, Watkins, McCoy, Muruthi, and Kiprono explored how and why immigrant East African women continue to support their families in their countries of origin through remittances. Implications of this qualitative investigation contribute to our understanding of the guilt and financial responsibilities some immigrant individuals and families may face as they try to establish themselves in the US while continuing to support family members in their countries of origin. Other investigations in this special section focus on the economic mobility through education among immigrant families. Lauderdale and Heckman examined the social and economic factors related to the concept of an "immigrant

Roudi Nazarinia Roy

Roudi.Roy@csulb.edu

Elizabeth M. Dolan

jfei.editor1@gmail.com

1 Department of Family and Consumer Sciences, California State University, Long Beach, CA, USA

2 University of New Hampshire, Durham, NH, USA advantage" in aspirations to complete a college degree, and the driving forces behind the desire for an upward mobility among immigrant Latino Families was investigated by Arellanes, Viramontez Anguiano and Lohman.

Two traditionally important components to family life in the US, parenting and marriage, were looked at by Mathew, Zhai, and Gao. In their investigation on Asian Indian parental practices Mathew et al. focused on parental practices among Asian American groups identifying the importance of family support in relation to parental nurturance for the parent. They found that parental self-efficacy had a significant mediating role in this relationship. While the traditional view in the US would be to focus on parenting after marriage, we have seen increases in non-marital birth in this country over the last two decades. Daniels, Kakar, and Chaudhuri contribute to the research on racial differences in the likelihood of unmarried mothers marrying their child's biological father. They examined maternal characteristics such a race, education, economic status, and child characteristics as well as other factors associated with the transition to marriage for unmarried mothers over a nine-year time period following the birth of the reference child. Racial difference are identified as a key finding, and the authors discuss critical implications for child welfare and intergenerational transmission of inequities.

We hope this special section contributes to the working knowledge of investigators focused on families and economic issues. As the US population becomes more diverse we must work to expand our knowledge and understanding of these diverse life expereinces. We must focus not only on our similaries but on the strengths that exist within our differences. 
Roudi Nazarinia Roy is an Assistant Professor at California State University, Long Beach, Department of Family and Consumer Sciences
Elizabeth M. Dolan is the Editor in Chief of the Journal of Family and Economic Issues, and Associate Professor Emerita from the University of New Hampshire 